\title{
KONTRIBUSI PENDAPATAN IBU RUMAH TANGGA TERHADAP KELUARGA PETANI DI DESA KIE ICI KECAMATAN IBU KABUPATEN HALMAHERA BARAT
}

\author{
Astrodein Sawangponto \\ Vicky Richard B. Moniaga \\ Ribka Magdalena Kumaat
}

\begin{tabular}{ll}
\hline Naskah diterima melalui Website Jurnal Ilmiah agrisosioekonomi@ unsrat.ac.id & $:$ Kamis, 25 April 2019 \\
Disetujui diterbitkan & $:$ Jumat, 26 April 2019 \\
\hline
\end{tabular}

\begin{abstract}
This study aims to determine the contribution of housewives to the income of farmer families in Kie ici Village, Mother District, West Halmahera Regency. This research was conducted for three months from October to December 2018. Data collection methods used were primary data and secondary data. The data taken is primary data using direct interview techniques and questionnaires for 30 farmer housewives. While secondary data was obtained from the Kie ici Village office, books available in stores and the internet such as google cendekia to access articles from various scientific journals and theses from other universities related to the topic of this research namely the contribution of housewives to the family. The results showed that the contribution of housewives' income to farmer households in Kie ici village in general housewives were able to contribute, at 39.68 percent, to family income which could be categorized as sufficiently fulfilling the family's need to live. ${ }^{*}$ eprm*
\end{abstract}

Keywords: contribution, housewives, farmer family income, Kie ici Village, West Halmahera.

\begin{abstract}
ABSTRAK
Penelitian ini bertujuan untuk mengetahui kontribusi ibu rumah tangga terhadap pendapatan keluarga petani di Desa Kie ici Kecamatan Ibu Kabupaten Halmahera Barat. Penelitian ini dilakukan selama tiga bulan dari bulan Oktober hingga Desember 2018. Metode pengumpulan data yang digunakan adalah data primer dan data sekunder. Data yang di ambil adalah data primer menggunakan teknik wawancara langsung dan kuesioner pada 30 ibu rumah tangga keluarga petani. Sedangkan data sekunder di peroleh dari Kantor Desa Kie ici, buku-buku yang tersedia di toko dan internet seperti google cendekia untuk mengakses artikel dari berbagai jurnal ilmiah dan skripsi dari perguruan tinggi lain yang berkaitan dengan topik penelitian ini yaitu kontribusi ibu rumahtangga terhadap keluarga. Hasil penelitian menunjukkan kontribusi pendapatan Ibu rumah tangga terhadap petani di Desa Kie ici secara umum ibu rumah tangga mampu berkontribusi, sebesar 39,68 persen, terhadap pendapatan keluarga yang dapat dikategorikan cukup memenuhi kebutuhan keluarga untuk hidup. ${ }^{*}{ }^{\text {eprm* }}$
\end{abstract}

Kata kunci: kontribusi, pendapatan, keluarga petani, Desa Kie Ici, Halmahera Barat

\section{PENDAHULUAN}

\section{Latar Belakang}

Masyarakat Indonesia sedang mengalami perkembangan dari masyarakat yang agraris ke masyarakat industri. Dalam proses tersebut pengintegrasian wanita dalam pembangunan, terutama wanita dari golongan ekonomi lemah, yang berpenghasilan rendah perlu digalakkan, melalui peningkatan kemampuan dan keterampilan untuk melakukan kegiatan- kegiatan ekonomi produktif, dalam rangka memperluas kesempatan kerja dan menciptakan usaha bagi diri sendiri.

Hal ini sangat perlu sebab wanita dari golongan masyarakat yang berpenghasilan rendah, umumnya melakukan peran ganda karena tuntutan kebutuhan untuk mempertahankan kelangsungan hidup bangsa. Wanita sebagai tenaga kerja ternyata memperoleh lapangan kerja yang lebih terbatas dari pria. Walaupun di Negara maju terdapat 70 
persen wanita yang bekerja dilapangan kerja yang terorganisasi ternyata hanya terkonsentrasi pada 25 lapangan kerja, yang hanya dapat dimasuki oleh jumlah sedikit wanita (Gusmaniar, 2013).

Wanita pada umumnya mempunyai peran ganda, baik bagi wanita yang berpendidikan rendah maupun wanita intelektual. Bagi wanita yang berpendidikan formal yang relative rendah, peran ganda itu didorong oleh kebutuhan ekonomi keluarga, dan untuk wanita intelektual peran ganda itu diarahkan pada pengembangan karier (Kumaat, 2011).

Kontribusi berasal dari bahasa inggris yaitu contribute, contribution maknanya adalah keikutsertaan, keterlibatan, melibatka diri maupun sumbangan. Berarti dalam hal ini kontribusi dapat berupa materi atau tindakan Peneliti sangat tertarik melakukan sebuah penelitian di Desa Kie-Ici karena jenis pekerjaan yang dilakukan ibu rumah tangga berfariasi yaitu : 1. Perdagangan (jual beli pala, warung dan kantin), 2. Keterampilan (menjahit dan kerajinan tangan lainnya), 3. PNS dan Swasta, dan 4. Jasa (asisten rumah tangga), sehingga membuat rasa semangat dan keingin tahuan peneliti muncul untuk meneliti di Desa Kie-Ici ini terkait seorang Ibu Rumah Tangga dapat menjalankan kontribusi sebagai ibu rumah tangga dan juga bekerja membantu meningkatkan ekonomi keluarga.

\section{Perumusan Masalah}

Berdasarkan uraian pada latar belakang, maka yang menjadi rumusan masalah adalah bagaimana kontribusi ibu rumah tangga terhadap pendapatan keluarga petani di Desa Kie-Ici ?

\section{Tujuan Penelitian}

Tujuan dari penelitian ini adalah untuk mengetahui kontribusi ibu rumah tangga terhadap keluarga petani di Desa Kie-Ici.

\section{Manfaat Penelitian}

Dapat menambah khasanah ilmu pengetahuan bagi peneliti khususnya dan pembaca pada umumnya. Serta dapat di jadikan bahan referensi bagi masyarakat, pemerintah, dan Fakultas pertanian program studi sosial ekonomi.

\section{METODE PENELITIAN}

\section{Waktu dan Tempat Penelitian}

Penelitian ini berlangsung selama 3 bulan sejak bulan Oktober sampai bulan Desember 2017. Tempat penelitian di Desa Kie-Ici Kecamatan Ibu Kabupaten Halmahera Barat.

\section{Metode Pengumpulan Data}

Data yang digunakan dalam penelitian ini adalah data primer dan data sekunder. Data primer merupakan data yang diperoleh dari wawancara dengan responden di lapangan tempat penelitian dalam hal ini adalah para pelaku usaha seperti : 1 . Perdagangan (jual beli pala, warung dan kantin), 2. Keterampilan (menjahit dan kerajinan tangan lainnya), 3. PNS dan Swasta, dan 4. Jasa (asisten rumah tangga). Data primer ini ditanyakan langsung pada para pelaku usaha, untuk kepentingan peneliti dan data tersebut belum pernah dipublikasikan sebelumnya. Data primer ini diperoleh dengan cara wawancaara langsung. Data sekunder didapat dari istansi dan kepala desa mengenai data yang diperlukan dalam penelitian ini yaitu seperti data tentang jumlah penduduk, data jenis pekerjaan dan lainya.

\section{Metode Pengambilan Sampel}

Metode pengambilan sampel dalam penelitian ini diambil secara sengaja (purposive sampling). Dimana sampel yang diambil sebanyak $30 \mathrm{ibu}$ rumah tangga yang masih mempunyai suami di Desa Kie-Ici Kecamatan Ibu Kabupaten Halmahera Barat.

\section{Konsep Pengukuran Variabel}

Variabel yang akan diukur dalam penelitian ini adalah:

1. Karakteristik Responden
a. Nama
b. Umur (tahun)
c. Jumlah tanggunan (org)
d. Pendidikan formal dan non formal

2. Jenis pekerjaan suami

3. Jenis pekerjaan anak

4. Upah dari jenis-jenis usaha yang diproduksi

5. Jumlah hasil usaha/responden/bulan

6. Pendapatan dalam keluarga
a. Pendapatan isteri (Rp/bulan)
b. Pendapatan suami (Rp/bulan)
c. Pendapatan anak yang sudah bekerja 


\section{Metode Analisis Data}

Data dianalisis secara deskriptif yang dikumpulkan dan disajikan dalam bentuk tabel. Dan untuk mengetahui kontribusi ibu rumah tangga terhadap pendapatan keluarga mengunakan analisis berikut:

Rumus:

$$
\text { Kontribusi Tbu Rumah Tangga }=\frac{\text { Pendapatan Ibu Rumah Tangga }}{\text { Total Pendapatan Keluarga }} 100 \%
$$

Dimana :

- Kontribusi Ibu Rumah Tangga dihitung berapa persentase dari semua pendapatan keluarga.

- Total Pendapatan keluarga = (pendaptan suami + pendapatan istri + pendapatan anak yang sudah bekerja). Pendapatan Ibu Rumah Tangga dapat dihitung Rp /bulan.

\section{HASIL DAN PEMBAHASAN}

\section{Deskripsi Lokasi Penelitian}

\section{Keadaan Geografis}

Desa Kie-Ici secara administratif termasuk dalam wilayah Kecamatan Ibu Tengga, Kabupaten Halmahera Barat, terletak diarah Utara Kabupaten Halmahera Barat, dengan jarak $5 \mathrm{~km}$, dari Kantor Kecamatan . Jarak Desa Kie-Ici dari Kantor Bupati Kabupaten Halmahera Barat $76 \mathrm{~km}$. Waktu tempu menuju pusat kota kecamatan 15 menit, sedangkan waktu tempuh menuju Ibu Kota Kabupaten kira - kira 2,5 jam. Desa Kie-Ici Terdiri dari 3 RT, Luas Wilayah.

Desa Kie-Ici adalah 66.250 Km dengan batas - batas sebagai berikut :

1. Selatan berbatasan dengan Desa Togola

2. Barat berbatasan dengan Desa Naga

3. Timur berbatasan dengan Desa Maritango

4. Utara berbatasan dengan Gunung Ibu

\section{Sejarah Desa}

Ada dua( 2 ) komodita masyarakat Tabaru yakni : masyarakat penduduk Tabaru Nyeku dan masyarakat penduduk Tabaru Adu. Perbedaan dari keduanya hanya pada kondisi Lingkungan dan letak geografi, area perkampungan serta sedikit dialek bahasa masyarakat.
Tabaru Nyeku bermukim di ara pegunungan (Nyeku puncak bukit), sedangkan Adu (dataran rendah). menurut kokene bahwa masyarakat Tabaru primitif (Togerebongo) adalah orang-orang nomaden dan masyarakat Tabaru hanya satu komoditas.

\begin{tabular}{|c|c|c|c|c|}
\hline No & $\begin{array}{c}\text { NAMA - NAMA } \\
\text { BAPAK / IBU }\end{array}$ & JABATAN & MASA JABATAN & KETERANGAN \\
\hline & Bunga (Bapak) & Himo & $1909-1920$ & Almarhum \\
\hline & $\mathrm{Ale}$ (Bapak) & $\begin{array}{l}\text { Himo } \\
\text { Himo }\end{array}$ & $1920-1923$ & Almarhum \\
\hline & Dioniki (Bapak) & Himo & $1923-1924$ & Almarhum \\
\hline & Nyinga (Bapak) & Himo & $1924-1926$ & Almarhum \\
\hline & Nikodemus Bunga (Bapak) & Himo & $1926-1950$ & Almarhum \\
\hline & Agustinus Bunga (Bapak) & Nyira & $1950-1960$ & Almarhum \\
\hline & Yonatan Nate (Bapak) & Karteker / pjs. & $1960-1962$ & Almarhum \\
\hline 8. & Herman Bunga (Bapak) & Karteker / pjs & $1962-1963$ & Almarhum \\
\hline & Martinus Pay (Bapak) & Karteker/pjs & $1963-1965$ & Almarhum \\
\hline 10. & Agustinus Bunga (Bapak) & Kepala Desa & $1965-1987$ & Almarhum \\
\hline 11. & Yulianus Hallo (Bapak) & Karteker / Pjs & $1987-1990$ & Almarhum \\
\hline 12. & Agustinus Bunga (Bapak) & Kepala Desa & $1990-1996$ & Almarhum \\
\hline & Yohan Sadja(Bapak) & & $1996-1997$ & Almarhum \\
\hline 14. & Remus.j. Pay (Bapak) & Karteker/Pjs & $\begin{array}{l}1990-1997 \\
1997-2002\end{array}$ & Almarhum \\
\hline 15. & Marthinus Hallo (Bapak) & Kepala Desa & $2002-2008$ & Masih Hidup \\
\hline 16. & Yoram Uang(Bapak) & Kepala Desa & $2008-2013$ & Masih Hidup \\
\hline 17. & Welly Lamidja (Bapak) & Kepala Desa & 2016 sekarang & Masih Hidup \\
\hline
\end{tabular}

\section{Demografi Penduduk Desa Kie ici}

Secara demografi jumlah penduduk Desa Kie-Ici pada tahun 2016 ada sebanyak 106 Kepala Keluarga (KK) dengan jumlah Penduduk 420 jiwa yang terdiri dari 207 laki - laki dan 213 perempuan. Rata-rata setiap keluarga terdiri dari 5 (lima) anggota rumah tangga berikut ini Tabel 2 berdasarkan jenis kelamin:

Tabel 2. Jumlah Penduduk Berdasarkan Jenis Kelamin

\begin{tabular}{ccc}
\hline Jenis Kelamin & Jumlah (Jiwa) & Persentase (\%) \\
\hline Laki-laki & 207 & 49,28 \\
Perempuan & 213 & 50,71 \\
\hline Jumlah & 420 & 100 \\
\hline Sumber: Data Statistik Desa Kie Ici, 2016
\end{tabular}

Kenyataan ini menunjukan bahwa tenaga kerja yang tersedia di desa Kie Ici mengisi peluang kerja sementara itu dilapangan kerja yang tersedia sebagian besar adalah di bidang pertanian termasuk peternakan serta kehutanan karen lahan pertanian cukup tersedia serta tanah yang subur.

Sebagian besar penduduk desa Kie Ici adalah tamatan sekolah dasar, 118 orang penduduk yang sekolah sebanyak 302 orang, menepati urutan pertama, dan urutan ketiga adalah penduduk yang tamat SMP sebanyak 72 orang, dan kedua adalah yang tamat SMU sebanyak 85 orang dan yang tamat akademi atau perguruan tinggi sebanyak 26 orang. Komposisi penduduk Desa Kie Ici berdasarkan tingkat pendidikannya dapat dilihat pada Tabel 3 berikut: 
Tabel 3. Jumlah Penduduk Menurut Tingkat Pendidikan

\begin{tabular}{llc}
\hline No & \multicolumn{1}{c}{ Tingkat Pendidikan } & Jumlah \\
\hline 1. & Tamat Akademi /PT & 26 \\
2. & Tamat SLTA & 85 \\
3. & Tamat SLTP & 72 \\
4. & Tamat SD & 118 \\
5. & Belum Tamat SD & 16 \\
6. & Tamat TK & 13 \\
7. & Tidak sekolah / belum sekolah & 90 \\
\hline \multicolumn{2}{c}{ Jumlah }
\end{tabular}

Sumber data : Profil Desa Kie-Ici

\section{Sarana Dan Prasarana}

Sarana perhubungan Desa Kie-Ici menuju Kabupaten Halmahera Barat dihubungkan dengan jalan darat dengan konstruksi jalan beraspal dan $6 \mathrm{~km}$ menuju Desa hanya sirtu yang keadaan jalannya rusak berat. sehingga memakan waktu yang cukup lama menuju ke Kabupaten Halmahera Barat.

Sedangkan dari pusat Desa menuju keseluruh dusun dihubungkan oleh jalan setapak, setapak darurat. Keadaan jalan dari kecamatan menuju ke Desa Kie-Ici jalan aspal yang rusak berat yang mengakibatkan mobilitas sebagian masyarakat untuk kegiatan berbisnis dan keperluan lainnya sulit.

\section{Karakteristik Responden}

\section{Umur Responden}

Umur merupakan salah satu faktor yang mempengaruhi perilaku dalam melakukan atau mengambil keputusan dan dapat bekerja secara optimal serta produktif. Seiring dengan perkembangan waktu, umur manusia akan mengalami perubahan dalam hal ini penambahan usia yang dapat mengakibatkan turunnya tingkat produktifitas seseorang dalam bekerja (Gusmaniar, 2003).

Tabel 4. Jumlah Responden Menurut Golongan Umur

\begin{tabular}{ccc}
\hline Umur (Tahun) & $\begin{array}{c}\text { Jumlah } \\
\text { (Responden) }\end{array}$ & $(\%)$ \\
\hline$\leq 21$ & 1 & 3,33 \\
$22-30$ & 10 & 33,33 \\
$31-40$ & 12 & 40,00 \\
$41-50$ & 5 & 16,66 \\
$51-60$ & 2 & 6,66 \\
\hline Jumlah & 30 & 100 \\
\hline
\end{tabular}

Sumber data : Profil Desa Kie-Ici

Tabel 4 menunjukan jumlah dan presentase Kontribusi Ibu rumah tangga berdasarkan umur. Hasil persentase umur responden pada Tabel 4 menjelaskan bahwa, umur dalam penelitian ini tidak berpengaruh terhadap Kontribusi ibu rumah tangga, semakin tua umur responden maka semakin berpengalaman.

Selain itu faktor yang membuat umur tidak berpengaruh terhadap Kontribusi ibu rumah tangga ialah tanggungan yang menjadi tanggungjawab responden sehingga membuat mereka harus bekerja keras untuk menghidupi setiap tanggungan mereka.

\section{Keadaan Sosial Ekonomi}

Sebagian besar keluarga di Desa Kie-Ici mempunyai mata pencaharian di bidang pertanian. Menurut catatan Monografi Desa Kie-Ici Tahun 2016, jumlah kepala Keluargayang bekerja di bidang pertanian sebanyak 278 orang, sedangkan sisanya bekerja di bidang lain seperti pengusaha, buruh, buruh pengangkutan, PNS dan sebagainya. Untuk jelasnya dapat dilihat pada Tabel 5 berikut:

\begin{tabular}{clc} 
Tabel 5. Penduduk menurut & Mata & Pencaharian Desa Kie \\
& ici & \\
\hline No & \multicolumn{1}{c}{ Mata Pencaharian } & Jumlah \\
\hline 1. & Petani & 278 \\
2. & Pengusaha / pedagang & 6 \\
3. & Petani buruh & 6 \\
4. & Buruh bangunan & 22 \\
5. & Pengangkutan & 6 \\
6. & PNS / ABRI / swasta & 12 \\
7. & Anak Sekolah & 80 \\
8. & Anak Balita & 10 \\
\hline & Jumlah & $\mathbf{4 2 0}$ Orang \\
\hline
\end{tabular}

Sumber : Data Statistik Desa Kie ici, 2015

Luas Wilayah Desa Kie-Ici keseluruhan sebesar $66.250 \mathrm{~km}$. Hal tersebut dapat di lihat dari luas lahan untuk kegiatan pertanian yaitu kebun sebanyak 9.143.3 Ha. sedangka lahan untuk hutan 49.250 Ha. Lahan yang di gunakan untuk jalan, lapangan, sungai, dan pekarangan 7.856.7 Ha. Perincian masing - masing pengunaan lahan di Desa Kie-Ici dapat di lihat pada Tabel 6 berikut ini:

\begin{tabular}{clc}
\multicolumn{2}{l}{ Tabel 6. } & Penggunaan Lahan \\
\hline No & \multicolumn{1}{c}{ Penggunaan Lahan } & Luas (Ha) \\
\hline 1. & Tanah perkebunan & $9.143,3$ \\
2. & Pekarangan & 6,7 \\
3. & Lahan Negara & 49.250 \\
4. & Lain - lain & 7.850 \\
\hline & Jumlah & $66.250 \mathrm{Ha}$ \\
\hline
\end{tabular}




\section{Kontribusi Ibu Rumah Tangga dalam Pendapatan Keluarga Petani}

Kontribusi adalah sumbangan atau bagian, kontribusi ibu rumah tangga terhadap pendapatan keluarga adalah besarnya sumbangan atau pendapatan yang diperoleh dari ibu rumah tangga terhadap keseluruhan pendapatan. Dari pendapatan besarnya kontribusi Ibu rumah tangga dapat dilihat pada Tabel 7

\begin{tabular}{|c|c|c|c|c|}
\hline \multirow{2}{*}{$\begin{array}{c}\text { Nomor } \\
\text { Responden }\end{array}$} & \multicolumn{3}{|c|}{ Pendapatan } & \multirow{2}{*}{$\begin{array}{c}\text { Persentase } \\
\text { Pendapatan } \\
\text { IRT }\end{array}$} \\
\hline & IRT & Bapak & Anak & \\
\hline 1 & 2.000 .000 & 2.500 .000 & 2.500 .000 & 28,57 \\
\hline 2 & 1.500 .000 & 2.000 .000 & - & 42,85 \\
\hline 3 & 2.500 .000 & 2.800 .000 & 1.700 .000 & 21,05 \\
\hline 4 & 2.500 .000 & 5.000 .000 & - & 33,33 \\
\hline 5 & 1.400 .000 & 2.500 .000 & 2.200 .000 & 22,95 \\
\hline 6 & 1.100 .000 & 700.000 & - & 61,11 \\
\hline 7 & 750.000 & 2.300 .000 & - & 24,59 \\
\hline 8 & 2.600 .000 & 2.100 .000 & - & 55,31 \\
\hline 9 & 1.900 .000 & 2.950 .000 & - & 39,17 \\
\hline 10 & 3.800 .000 & 3.250 .000 & - & 53,90 \\
\hline 11 & 3.750 .000 & 3.500 .000 & - & 51,72 \\
\hline 12 & 1.815 .000 & 1.700 .000 & - & 00,51 \\
\hline 13 & 800.000 & 3.100 .000 & - & 20,51 \\
\hline 14 & 2.350 .000 & 4.200 .000 & - & 35,87 \\
\hline 15 & 1.600 .000 & 1.850 .000 & - & 46,37 \\
\hline 16 & 3.500 .000 & 2.400 .000 & - & 59,32 \\
\hline 17 & 2.100 .000 & 2.150 .000 & - & 49,41 \\
\hline 18 & 1.500 .000 & 2.250 .000 & - & 40.00 \\
\hline 19 & 700.000 & 2.500 .000 & - & 21,87 \\
\hline 20 & 1.800 .000 & 2.150 .000 & - & 45,56 \\
\hline 21 & 800.000 & 3.500 .000 & - & 18,60 \\
\hline 22 & 2.150 .000 & 2.400 .000 & - & 27,25 \\
\hline 23 & 2.300 .000 & 2.450 .000 & - & 48,42 \\
\hline 24 & 2.700 .000 & 2.350 .000 & - & 53,46 \\
\hline 25 & 1.040 .000 & 3.950 .000 & 1.000 .000 & 17,36 \\
\hline 26 & 1.950 .000 & 1.200 .000 & - & 61,90 \\
\hline 27 & 3.500 .000 & 3.600 .000 & - & 49,29 \\
\hline 28 & 3.850 .000 & 2.900 .000 & 1.680 .000 & 45,67 \\
\hline 29 & 2.100 .000 & 2.250 .000 & 3.250 .000 & 27,63 \\
\hline 30 & 600.000 & 1.820 .000 & - & 24,79 \\
\hline Total & 59.655 .000 & 78.320 .000 & 12.330 .000 & $39,68 \%$ \\
\hline
\end{tabular}

Tabel 7 menunjukan bahwa berdasarkan data total dari pendapatan Ibu rumah tangga terhadap pendapatan keluarga, maka kontribusi pendapatan ibu rumah tangga terhadap pendapatan keluarga adalah sebesar 39,68\%. Pada tabel diatas dapat juga dilihat bahwa pendapatan Ibu rumah tangga terhadap keluarga yang tertinggi adalah sebesar Rp 3.850 .000 /bulan. Sedangkan pendapatan Ibu rumah tangga yang terendah terhadap keluarga adalah sebesar Rp 600.000 /bulan.

Dan juga kalau dilihat pada Tabel 7 tersebut dari kontribusi Ibu rumah tangga Cuma ada 6 anak yang sudah berkontribusi. Jumlah pendapatan keseluruhan dari masing-masing pekerjaan anak tersebut adalah sebesar $\mathrm{Rp}$ 12.330.000. Hal ini menunjukan bahwa dari 30 responden dari 6 keluarga tersebut ada 6 anak yang sudah mempunyai pekerjaan dan ke 6 anak tersebut sudah dapat berkontribusi.

\section{Pendapatan Responden}

Pendapatan merupakan sumber penghasilan seseorang yang memenuhi kebutuhan sehari-hari dan sangat penting artinya bagi kelangsungan hidup dan penghidupan seseorang secara langsung maupun tidak langsung (Suroto, 2000).

Tabel 8. Pendapatan Ibu Rumah Tangga

\begin{tabular}{cccc}
\hline No. & Pendapatan IRT & Jumlah & Persentase $\%$ \\
\hline 1. & $\leq 2$ & 11 & 36,66 \\
2. & $2,1-3$ & 14 & 46,66 \\
3. & $\geq 3,1$ & 5 & 16,66 \\
\hline & Jumlah & 30 & 100 \\
\hline
\end{tabular}

Sumber : Diolah dari Data Primer, 2018

Berdasarkan Tabel 8 dapat dilihat pendapatan responden yang memiliki persentase terbanyak yaitu 2.500 .000 sampai 3.000 .000 yaitu $46,66 \%$, diikuti 11 responden dengan pendapatan $\leq 2.00 .000$ yaitu $36,66 \%$, dan terakhir 5 responden memiliki pendapatan yaitu $\geq 3.000 .00-3.950 .000$ yaitu $16,66 \%$.

Dari hasil penelitian di Desa Kie ici bahwa kontribusi ibu rumah tangga memberikan kontribusi bagi pendapatan keluarga yaitu sebesar 39,68 \% dalam 1 bulan dari total keseluruhan pendapatan kelurga. Hal ini menunjukan bahwa kontribusi Ibu rumah tangga merupakan sangatlah penting terhadap keluarga petani yang ada di Desa kie ici. Dan jika dilihat dari Umur Kontribusi Ibu rumah tangga terbanyak ada pada usia produktif 31 sampai 40 Tahun yaitu sebesar 40,00 \%. Sedangkan jika dilihat dari tingkat pendidikan kontribusi ibu rumah tangga terbanyak terdapat pada tingkat pendidikan SD yaitu 28,09 \%, karena tingkat pendidikan tidak mempengaruhi kreativitas ibu rumah tangga. Dan jika dilihat dari jumlah pendapatan anak yang sudah dapat bekerja atau yang sudah dapat berkontribusi pada keluarga yaitu sebesar $27,63 \%$.

\section{KESIMPULAN DAN SARAN}

\section{Kesimpulan}

Hasil penelitian menunjukan bahwa kontribusi ibu rumah tangga terhada pendapatan keluarga di Desa Kie ici adalah sebesar 39,68\% perbulan. 


\section{Saran}

1. Untuk pemerintah kiranya dapat memperhatikan dan memberikan dukungan kepada ibu rumah tangga khususnya berkontribusi dalam hal meningkatkan pendapatan keluarga petani.

2. Penelitian ini hendaknya dapat dijadikan patokan bagi ibu-ibu rumah tangga dalam mengerjakan sesuatu bahwa selain pekerjaan sebagai isteri dan ibu dalam keluarga dapat juga berperan dalam usaha mencari nafkah guna menambah pendapatan keluarga.

\section{DAFTAR PUSTAKA}

Gusmaniar. 2013. Kontribusi Pendapatan Wanita Peternak Kelinci Terhadap Total Pendapatan Keluarga di Kelurahan Salokaraja Kecamatan Lalabata Kabupaten Soppeng. Skripsi Fakultas Peternakan Universitas Hasanuddin Makasar. Repository.unhas.ac.id. Diakses tanggal 6 Oktober 2017.

Kumaat R. M. 2011. Kontribusi Ibu Rumah Tangga Terhadap Pendapatan Keluarga Di Desa Kinilow Kecamatan Tomohon Utara. Jurnal Volume 7 Nomor 3, September 2011: 50 - 55. Ejournal Unsrat.ac.id. Diakses tanggal 2 Oktober 2017.

Suroto. 2000. Strategi pembangunan dan Perencanaan Perencanaan Kesempatan Kerja. Yogyakarta: Gajah Mada Univercity. 